\title{
Changing Vietnamese consumer culture today - issues for the sustainable development of Vietnamese enterprises
}

\author{
Nguyen Thi Minh $\mathrm{Ngoc}^{1, *}$, and Anna Kopytova ${ }^{2}$ \\ ${ }^{1}$ Institute of Sociology, Vietnam Academy of Social Sciences, 1 Lieu Giai street, Ba Dinh district, \\ Hanoi, 10000, Vietnam \\ ${ }^{2}$ Tyumen Industrial University, Volodarskogo str., 38, Tyumen, 625000, Russia
}

\begin{abstract}
The paper, based on the analysis of changes in Vietnamese consumer culture in the context of globalization and international integration, provides suggestions for Vietnamese enterprises to access and dominate the domestic market. It can be seen that, Vietnamese people now tend to choose products made in Vietnam more than imported products of the same type because Vietnamese products meet the tastes of Vietnamese people and have reasonable prices for financial conditions of the majority Vietnamese people. Vietnamese enterprises have many advantages in accessing and dominating the domestic market, but many businesses have not paid enough attention.
\end{abstract}

\section{Introduction}

Over the past years, Vietnam has made great changes in its economic, political and social aspects. Socio-economic development is an important factor that makes the change in Vietnamese consumer culture clearly reflected in the change of consumption habits. The change of consumers' habits sets a new development direction for Vietnamese enterprises. In this article, we analyze in depth the current consumption habits of Vietnamese people, thereby, suggesting the issues that enterprises need to adapt to get the right direction for appropriate business development with consumer demand, dominate the Vietnamese market.

\section{Materials and methods}

Firstly, the article approaches the issue of consumer culture from the perspective of consumer culture theory. This theory analyzes and interprets the dimensions of experience, ideas, materials and the interdependent aspects of marketing and consumption in its numerous manifestations in modern society [1]. It is used to explain cultural and structural processes and extrapolate sociological or anthropological models in consumer relations [3, $6,8]$ and consumer interactions $[2,4,10]$ thereby reconfiguring the consumer market.

\footnotetext{
${ }^{*}$ Corresponding author: ngocnminh@gmail.com
} 
Secondly, the article uses quantitative and qualitative research methods. The quantitative and qualitative data used in this article are the results of a survey of the project "Vietnamese consumer culture in the context of globalization and international integration", under the program: Science National science and technology in the 2016-2020 period. key issues on social sciences and humanities for socio-economic development". Code: KX.01 / 16-20. The survey was conducted in 8 provinces across the country to select representatives of key economic regions including: Hanoi; Bac Ninh; Quang Ninh; Nghe An; Ha Tinh; Danang; Binh Duong; Tien Giang; and Ho Chi Minh City. The number of survey questionnaires is 3000 . The social characteristics of the survey team are as follows:

Table 1: Gender, aging, education, marrige status

\begin{tabular}{|c|c|c|}
\hline & Nunber & $\%$ \\
\hline Male & 970 & 32.3 \\
\hline Female & 2030 & 67.7 \\
\hline $20-29$ & 363 & 12.1 \\
\hline $30-39$ & 722 & 24.1 \\
\hline $40-49$ & 589 & 19.6 \\
\hline $50-59$ & 730 & 24.3 \\
\hline $60-69$ & 596 & 19.9 \\
\hline Primery School & 132 & 4.4 \\
\hline Junior high School & 580 & 19.3 \\
\hline High School & 1159 & 38.6 \\
\hline Intermediate, College & 338 & 11.3 \\
\hline University & 624 & 20.8 \\
\hline Uper University & 167 & 5.6 \\
\hline Unmarrige & 213 & 7.1 \\
\hline Marige & 2417 & 80.6 \\
\hline Divorced / Widowed & 370 & 12.3 \\
\hline
\end{tabular}

Source: Survey of the project, 2018 by Institute of Sociology

In addition, the article uses in-depth interviews with 50 people who are not part of the quantitative survey group. The results of in-depth interviews are concrete evidence for the data obtained from quantification.

Thirdly, the study of consumer culture of Vietnamese people today cannot be separated from the economic context of the country and the world. The paper uses research on domestic and world economic situation. Globalization, prices of goods and the development of developing countries are also an important factor of the current world economy. The integration process is expected to continue even as commodity prices have recently slowed down or decreased. In addition to the small impact of fluctuations in commodity prices, the increasing integration of developing countries is mainly due to better institutional quality, increased financial depth and along with the outside liberalization process continues to take place [7]. The recent rapid increase in global integration is due to the increase in prices of many goods, with an overall growth of about $75 \%$ compared to 2000 [7]. The world economy has a direct impact on Vietnam's economy today. The external economic environment is currently considered to be favorable for the Vietnamese economy however, the risks are increasing. According to the World Bank, global demand and trade growth are strong but are expected to slow down in the context of higher commodity prices, tighter capital mobilization conditions and increased policy uncertainty. Global GDP growth is expected to reach $3.1 \%$ in 2018 but will slightly decline to an average of 3\% in the period 2019-2020 when advanced economies have gone through an upward cycle. Growth in the East Asia and Pacific region is expected to moderate slightly to $6.3 \%$ in 2018 and then reach an average of $6.1 \%$ over the period of 2019-2020, mainly reflecting the continuing decline in China [9]. Despite many achievements in economic 
growth, Vietnam's economy still has many shortcomings and limitations. Despite great efforts in poverty reduction, the poverty rate is still high among ethnic minority communities in remote areas [5]. State-owned corporations still hold monopolies or dominate the market without effective monopoly supervision. The state intervenes too much in the market at different levels in a lack of publicity and transparency, creating favorable conditions for the development of nefarious groups. The state maintains monopoly on many products and services without effective control mechanisms, distorting business environment, unfair competition, creating opportunities for some individuals to rise above in when most small and medium enterprises do not have conditions to develop [5, p. 35].

Fourth, the Political Report of the Vietnam Communist Party Congress 12th is an important basis for analyzing and evaluating the achievements of Vietnam in the previous period and development directions in the coming time. The report shows the specific orientation of the country development strategy in each field. Thereby, developing consumer culture how to build consumption habits for Vietnamese people associated with the country's sustainable development factors.

Fifthly, Vietnamese consumer culture is considered and analyzed in order to implement the Politburo's Notice of Conclusion No. 264-TB / TW, dated July 31, 2009, on the campaign "Vietnamese people favor first use Vietnamese goods." The purpose of promoting patriotism, self-reliance, national self-respect, building Vietnamese consumer culture and producing many Vietnamese products of high quality, aggreg and satisfaction domestic consumer demand and export.With the spirit of mobilizing all Vietnamese organizations and individuals instead of using imported goods from foreign countries with the quality, price and use of products equivalent to Vietnamese goods, please give priority to using Vietnamese goods. This is an important content for the article to have suggestions for Vietnamese enterprises to target the domestic market.

\section{Result}

The first dimension of consumer culture change of Vietnamese people is the changing in consumption demand. The demand of "full eating and warm clothes" has previously been transformed into the demand of "delicious eating and nice clothes". Therefore, consumption patterns are used by some people as a measure of social status, the level of individual success in society. Consumer demand is not only directed at the product's usability but also to its social value. It is the need to use brand and foreign goods to affirm the rank of a significant number of Vietnamese people today.

The transformation of the economic structure after the "Doi Moi" 1986 was the basis for the change of consumption needs of Vietnamese people. Under the subsidized central bureaucratic economy, goods are mainly distributed. The product distribution mechanism does not allow consumers the right to choose products according to personal needs and preferences. In this period, consumer demand mainly focused on essential goods, directly related to daily life.

The economic transition to a state-oriented market economy model facilitates the diversity of economic sectors. As a result, the commodity market has developed with various forms to create favorable conditions for consumers and at the same time promote to increase and change consumer demand of Vietnamese people. The market economy with the diversity of social components is the factor that creates social stratification. Undeniably, social stratification has become more and more profound in Vietnamese society. The gap between rich and poor is growing. The gap in social groups' distance within the stratification system confirms the difference in financial ability to pay for consumption of different social groups. Consumer demand in an era of homogeneous subsidy bureaucracy 
has now become diverse with large differences between social groups, depending on economic capacity.

Consumption demand of Vietnamese people in social groups is constantly changing, depending on the extent of the social groups' financial ability. Social groups with low financial capacity, even if they have desires, necessities and preferences for consuming high-quality goods, or luxury goods, cannot afford to meet them. Therefore, consumption decisions are not made and consumer demand in this case remains zero. In contrast, social groups of the upper class with strong and stable financial capacity have no need to consume poor quality goods or brands that do not affirm their social status. Thus, the need to "use brand name is to affirm the style" is also from the need to affirm the social position and shape of the individual. Demand for goods that are not appropriate for social class is also considered to be zero. The relevance of desire, necessity, and consumer interest, and financial responsiveness are governed by a variety of other personal and social factors.

'I often use branded goods. I'm in this position if I don't use the brand name other people look at me be nothing. When I wear a suit, I have to choose how I go through the restaurant or the hotel, the staff there must bow their heads. They just look at the clothing brand, style is knowing the position at the top and need to serve, how to behave? ... "(Male, 52 years old, officer, Hanoi).

However, the majority of Vietnamese still prefer to choose domestic products. The results of our survey indicate that the last time to conduct the purchase of imported foods of respondents with items: rice, vegetables / tubers, fruits of all kinds, meat (beef, chicken ), milk of all kinds, confectionery are different. Most of the respondents did not buy these imported foods. The product with the highest rate of buying imported products is fruit $(27.5 \%)$ and the latest purchase has the highest rate of less than 1 month. Milk and confectionery are the two items with the highest rate of choosing to use imported products after fruits $(22.4 \%$ and $22.5 \%)$ with the highest percentage of the latest purchases of less than 1 month. Vietnamese people tend to like to use Vietnamese fruits, but when they give them, they choose imported fruits. This is the psychology of favoring foreign goods, consuming foreign goods as affirmation of class and brand. "I still believe in Vietnamese products, I believe in the origin and quality, I still believe in Vietnamese products. I buy Vietnamese fruits and vegetables while I buy foreign goods for others. Gifts need a higher price. " (Male, bachellor, sales supervisor).

Among those who do not use imported goods in items: rice, vegetables / tubers of all kinds, fruits of all kinds, meat (beef, pork, chicken), milk of all kinds, confectionery, the reason they use Vietnamese goods according to the survey is that: firstly, Vietnamese should use Vietnamese goods; secondly, Vietnamese products are easy to buy; and the third is Vietnamese favorites. "I mainly use domestic goods, but foreign products I do not care much. In my opinion, milk must be competitive because of better quality. Normal food items don't have to compete. " (Male, 1960, president of the Veterans Association)

Better economic conditions, Vietnamese consumers have paid more attention to product quality. Consumers in Vietnam now have a change in the level of knowledge about the product. From improving knowledge, consumers in general and Vietnamese consumers in particular have paid more attention to the origin of products and origin of goods and considered it as one of the important criteria for quality assessment and make a consumer decision. However, it can not be denied that in the current Vietnamese market, non-origin goods are very popular. Usually, prices of non-origin goods are often much cheaper than those with clear certificates of origin. In the past, when consumer confidence was not degraded, consumers placed high faith in the quality targets the producers set out, trusting manufacturers to supply quality, non-toxic products, harm in use. At that time, the issue of product origin and origin of ingredient was not the key issue when choosing a product. The problem that consumers mainly care about is the price, the convenience of buying and 
selling products, the usefulness of products. In the current context, the quality and origin of products is a factor of particular concern before making consumer decisions. You can find out about product quality from the information and specifications written on the packaging. If in the past, the circulation of non-labeled goods was popular in the market and easily accepted by consumers, then today the products on the market need to have labels. Clear marks with full criteria on product components, manufacturing date and expiry date. With imported products, not all imported brand names are equally accepted by consumers.

Vietnamese people are also aiming at green consumption trend to promote the development of green economy. In Vietnam, regulations related to green consumption have been integrated in many contents of policies and regulations of the Party and the State on sustainable development. In the socio-economic development strategy of Vietnam in the period of 2011-2020, consumption issues associated with environmental protection are set out, which can be seen as an aspect of sustainable consumption. mode of environmental protection, associating environmental protection tasks and objectives with socio-economic development; attaching importance to developing a green and environmentally friendly economy; implementation of sustainable production and consumption; gradually develop clean energy and clean consumption ". Green consumption not only requires consumer products to ensure green standards, that is, promote the development of a green manufacturing enterprise system, but also requires consumers to conduct consumeroriented products. Environmentally friendly, as a general culture and consumer culture in particular.

Changes in consumer habits are also reflected in the change in the way consumers place. For example, with food items, previously the favorite shopping places for consumers were toad markets, small markets, street vendors ... and large markets. Currently, the three most popular shopping places for Vietnamese consumers are big markets, shops near homes and supermarkets. Big Market is a place with a variety of goods, easy to choose enough quantity of goods in one shopping. Therefore, the big market is one of the ideal places to shop. The form of shopping in the big market is traditional. Goods in the market are diverse, not only in terms of types and quality, but also because they are the convergence of many types of businesses. The prices of goods in big markets are also different. Big market is a place that can meet the consumption needs of all social classes. Big markets have many advantages, but not always consumers can shop everyday at the big market, especially with those who are far from the big market. In order to save time spent on food shopping, people who are far away from the big market often choose shopping places near the house. The market near the house is mostly a toad market, meeting with a convenient time with shopping time of the people around it, for example, early in the morning before work and the evening after work. The size of the market near the house / toad market is usually small. Goods in this market are not many categories, usually only focusing on common food categories used for daily meals. The market near the house has the advantage of having a lot to serve the population in a small scale so it is convenient for transportation, travel, saving time for consumers. With a daily supply of food, a market near the house / toad market is an appropriate choice. Supermarkets are a popular new type of market recently. Products in the supermarket are diverse in types and quality of goods in the supermarket ensure a clear origin. Foodstuffs in supermarkets are mainly frozen goods. Consumption of fresh goods is still a traditional habit of Vietnamese people in food selection. Recently, some types of fresh food, used in the day at supermarkets are preferred by consumers for food safety. Supermarkets are also the place to supply a variety of imported food products. However, the price of food in the supermarket is higher than the traditional market so not everyone can choose a supermarket as a shopping place. In the 4.0 period, with the strong support of information technology, online shopping is becoming more and more popular but it is still not a popular form of food shopping for Vietnamese people. Supermarket is 
now a place chosen by many consumers because of its abundant goods and guaranteed quality, high safety, and clear origin goods. However, most products at supermarkets have higher prices than similar products in the market.

Table 2: Food shoping place

\begin{tabular}{|c|c|c|c|}
\hline & $\mathrm{N}$ & $\%$ & $\%$ theo trường \\
\hline Supermarket & 1692 & $23.0 \%$ & $56.4 \%$ \\
\hline Market & 740 & $10.0 \%$ & $24.7 \%$ \\
\hline Big market & 1978 & $26.8 \%$ & $65.9 \%$ \\
\hline Market nearby house & 1780 & $24.1 \%$ & $59.3 \%$ \\
\hline Stress vendor & 156 & $2.1 \%$ & $5.2 \%$ \\
\hline From the countryside & 268 & $3.6 \%$ & $8.9 \%$ \\
\hline Online & 71 & $1.0 \%$ & $2.4 \%$ \\
\hline Neighbor & 309 & $4.2 \%$ & $10.3 \%$ \\
\hline Unstable & 116 & $1.6 \%$ & $3.9 \%$ \\
\hline Householder & 261 & $3.5 \%$ & $8.7 \%$ \\
\hline Total & 7371 & $100.0 \%$ & $245.7 \%$ \\
\hline
\end{tabular}

Source: Survey of the project, 2018 by Institute of Sociology

Implications for Vietnamese enterprises to access and dominate the domestic market

Firstly, Vietnamese people tend to choose to use Vietnamese products instead of imported products of the same type. This is an advantage for Vietnamese enterprises in accessing and dominating the domestic market. Currently a number of industries such as textiles, footwear, food ... many Vietnamese enterprises focus on export. In fact, these enterprises have guaranteed the quality standards of demanding markets around the world. This shows that their products meet the quality and design requirements for Vietnamese people, but the business has ignored the domestic market. Many Vietnamese nowadays prefer to buy Made in Vietnam for export. The need to find Made-in-Vietnam products for export in the market has created favorable conditions for many subjects to produce fake goods of poor quality and to label export goods for sale on the market.

Secondly, the reason Vietnamese people like to use Vietnamese goods is because they like Vietnamese goods, Vietnamese goods are suitable for Vietnamese tastes and prices of Vietnamese goods are suitable for economic conditions of most Vietnamese people. The trend of using branded goods is to show style and class, so imported goods, especially imported goods from famous brands, are often used as gifts and for a few rich people. Vietnamese enterprises are fully qualified to dominate the market for goods for the middle and lower class.

Third, in fact, the current import market is too diverse in terms of products, brands and quality. Some imported goods of low quality (usually made in China) are not favored by consumers. In some border areas of Vietnam - China, many items of fact are Chinese use the name made in Vietnam to attract consumers. As such, Vietnamese enterprises need to fill gaps in the domestic market to avoid fake goods to reduce the reputation of goods made in Vietnam.

Fourthly, Vietnamese consumers currently attach great importance to product quality and product origin. Vietnamese enterprises need to clearly indicate the origin of product components to win consumers' trust. When consumers believe in the quality of Vietnamese products, the choice of Vietnamese products for consumers ò Vietnamese people will be significantly higher due to the superior characteristics of Vietnamese goods that are suitable for tastes and prices.

Fifth, the survey showed that Vietnamese consumers are now aware of green consumption. They accept to pay a higher price for the product if it is a green product that guarantees the quality for the consumer and the environmental protection. Therefore, Vietnamese businesses need to have a plan to gradually change production lines to ensure 
the supply of green products to the market to meet consumer requirements. This is also a development trend to ensure the sustainable development of enterprises in the spirit of the Political Report of the 12th Party Congress.

Sixthly, Vietnamese enterprises have not really focused on Vietnamese branding. A number of Vietnamese fashion enterprises have successfully built their brands and created a good reputation among consumers. Branding is an important issue for businesses to ensure sustainable business development. Brand affirms consumer confidence in the product. The brand itself is also a value that creates long-term profits for businesses.

\section{Conclusion}

Vietnamese society after more than 30 years of renovation has made great progress, especially in the field of socio-economic. The change of economic life changes consumption habits of Vietnamese people. In the past, Vietnamese consumers were aiming to consume to meet the essential values of daily life, but now Vietnamese consumers do not just stop at values that ensure basic living needs. They are interested in the social values of consumption, thereby satisfying their spiritual needs, interests, desires, bringing joy, and also a way to assert social position. After a long time of putting emphasis on economic development, sustainable development is now the focus of every nation. A green economy is set, followed by a change in consumer awareness and behavior. Vietnamese consumers in the context of globalization and international integration are also moving towards green consumption. This is the consumption trend of Vietnamese people in the coming time because green consumption is both meeting the internal needs of consumers, providing clean products, ensuring consumers' health, and meeting the requirements. Bridge to protect the common living environment of the community.

Vietnamese enterprises have many advantages in accessing and dominating the domestic market. However, many enterprises have not yet paid attention to the potential of this market. The Government of Vietnam has always paid attention to creating favorable conditions for Vietnamese enterprises to develop the domestic market, meeting the consumption needs of Vietnamese people. "Vietnamese people give priority to using Vietnamese goods" is the spirit of the campaign to use Vietnamese goods launched by the Politburo. International integration and export-oriented are necessary development directions, but Vietnamese enterprises need to pay attention at the same time to focus on the domestic market. This is a key trend to ensure sustainable development for businesses in Vietnam.

The paper is the product of the project "Vietnamese consumer culture in the context of globalization and international integration" under the program: National science and technology in the 2016-2020 period. key issues on social sciences and humanities for socio-economic development". Code: KX.01 / 16-20.

\section{References}

1. E. Arnould, C. J. Thompson, Journal of consumer research, 31(4), 868 - 882 (2005), DOI: https://doi.org/10.1086/426626

2. J.C. Coupland Journal of consumer research, 32(1), 106 - 118 (2005), DOI: https://doi.org/10.1086/429604

3. A.M. Epp, L.L. Price, Journal of consumer research. 35, 50 - 70 (2008), DOI: https://doi.org/10.1086/529535 
4. J.L. Lastovicka, K.V. Fernandez, Journal of consumer research, 31(4), 813 - 823 (2005). DOI: https://doi.org/10.1086/426616

5. Lê Đăng Doanh. Vietnam's economy thirty years after renovation: needs a second innovation, in Vietnam after 30 years of innovation achievements and prospects. (Hà Nội: Hồng Đức publishing house, 2016)

6. C. Mathwick, C. Wiertz, K.D. Ruyter, Journal of consumer research, 36, 32-49 (2008). DOI: https://doi.org/10.1086/523291

7. N., Spatafora, I. Tytell, Báo cáo triển vọng kinh tế thế giới, chương 5 . Quỹ tiền tệ quốc tế (2008).

8. B.D. Wooten, Journal of consumer research, 33, 188-198 (2006), DOI: https://doi.org/10.1086/506300

9. World bank 2018, Review updated situation of Vietnam's economic development. world bank group, (2018)

10. C. Yu, Journal of consumer research, 35(6), 925-940 (2009)

11. V. Lukosius, Journal of Consumer Marketing, 21(6), 435-437 (2004), DOI: https://doi.org/10.1108/07363760410558708

12. S. Subrahmanyan, J.T. Gomez Arias, Journal of Consumer Marketing, 25(7), 402-412 (2008), DOI: https://doi.org/10.1108/07363760810915617 